\title{
Design of a circumscribing polygon wide bandgap based integrated modular motor drive topology with thermally decoupled windings and power converters
}

\author{
Abdalla Hussein Mohamed \\ Electromechanical, Systems and Metal Engineering \\ Ghent University \\ Ghent, Belgium \\ Flanders Make@UGent - core lab EEDT-MP \\ EPE \\ Cairo University \\ Cairo, Egypt \\ a.hussien.rashad@gmail.com \\ Hendrik Vansompel \\ Electromechanical, Systems and Metal Engineering \\ Ghent University \\ Ghent, Belgium \\ Flanders Make@UGent - core lab EEDT-MP \\ Hendrik.Vansompel@UGent.be \\ Peter Sergeant \\ Electromechanical, Systems and Metal Engineering \\ Ghent University \\ Ghent, Belgium \\ Flanders Make@UGent - core lab EEDT-MP \\ Peter.Sergeant@UGent.be
}

\section{Keywords}

$\ll$ Integrated motor drives $\gg, \ll$ Wide Bandgap devices $\gg, \ll \mathrm{GaN} \gg, \ll \mathrm{DC}$ link capacitor $\gg, \ll \mathrm{CFD} \gg$

\begin{abstract}
In this paper, the design of an integrated modular motor drive topology based on the circumscribing polygon of the outer surface of the conventional cylindrical housing is introduced from the mechanical and the thermal point of view. The design of the shared machine and converter cooling system is optimized from the thermal point of view using computational fluid dynamics (CFD) simulations. A wide bandgap, specifically Gallium Nitride (GaN), based half-bridge converter module is designed and implemented for integration. For a case study of a machine of outer radius $75 \mathrm{~mm}$, axial length $80 \mathrm{~mm}$ and six stator modules, the resulted surface area for each converter module is $80 * 87 \mathrm{~mm}^{2}$. The size of the converter module was reduced so as to exactly match the available surface around the machine. A method for the calculation of the maximum power per module is introduced resulting in $1032 \mathrm{~W}$ per module for the case study considered in the paper. A method for the DC-link capacitor design is introduced and the influence of the stator phases connections on the DC-link current stress is explained. Experimental measurements are done on one segment of the proposed integration topology.
\end{abstract}




\section{Introduction}

Integrated modular motor drives (IMMDs) combine the segmented machine stator with the driving converter of each segment into the same housing [1]. This physical integration results in the elimination of the separate heatsink and enclosure needed for the driving converter. Moreover, the long cables connecting the converter output to the machine winding can be also eliminated. On the one hand, the elimination of such components reduces the total weight, volume and cost of the whole drive [2]. On the other hand, the elimination of the cables improves the electromagnetic compatibility (EMC) of the whole system [3]. Due to the existence of the converter modules near to the heat generation sources of the machine (winding, core), challenges regarding the stable mechanical mounting and the sufficient cooling of both the machine and the converter modules should be handled [4]. The modularity of the stator structure and the driving converter provides many advantages over the conventional drives. As the total drive power is divided on all the modules, the electrical and the thermal stresses of the semiconductor devices reduces, which in turn improves the reliability of the whole drive. By proper connection of the modules, the fault tolerance of the whole drive can be greatly enhanced [5].

In IMMD, the ambient temperature of the power converter switches is expected to be high due to the proximity of the power semiconductor devices to the winding and/or the core of the machine. This high ambient temperature reduces the amount of temperature rise allowed for the semiconductor junction until reaching the rated junction temperature. The maximum amount of junction temperature rise allowed depends on the power dissipation in the switch, the ambient temperature, the rated junction temperature and the thermal resistance from the junction of the semiconductor device to the ambient. Among the three commercially available semiconductor technologies ( $\mathrm{Si}, \mathrm{GaN}, \mathrm{SiC}$ ), the wide bandgap (WBG) devices $(\mathrm{GaN}, \mathrm{SiC})$ represent an excellent candidate for the IMMD applications for their low conduction and switching losses, high rated junction temperature and high thermal conductivity [6]-[7]-[8].

IMMD can be classified according to the location of the power converter module with respect to the machine into: axially stator iron mounted (ASM), radially stator iron mounted (RSM), axially housing mounted (AHM) and radially housing mounted (RHM) [2]. The RSM and ASM provide a more compact integrated drive with higher cooling challenges [9]

In this paper, a RSM modular topology is proposed, designed and one module is implemented to prove the concept. The paper is organized as follows: the first section introduces the idea and provides mechanical design details, section two elaborates the design of the power converter module, section three explains the thermal modelling and design of the proposed integration topology, section four provides an algorithm for the calculation of the maximum power per module and the last section is dedicated for the experimental results.

\section{Mechanical construction of the proposed circumscribing polygon topology}

In IMMD, every module consists of a stator tooth along with its driving converter module and a shared cooling system for evacuating heat from both the stator tooth and the converter module. The shared cooling system should be capable of: thermally decoupling the power converter module and the machine tooth, providing a mechanically stable surface for mounting the converter printed circuit board (PCB) and creating a good thermal contact between the thermal pad of the transistors and the cooling surface. Fig. 1 (left) shows the proposed integration topology for a six stator coils machine. The proposed shared cooling of the machine and the power converter has a polygon shaped radial cross sectional area with number of sides equal to the number of the stator coils. The heat generated by the machine and the power converter is evacuated by the cooling fluid pumped in the cooling channel. Fig. 1 (right) shows the heat flux path from the stator and the power converter to the ambient.

\section{Power converter module design}

In this section, the calculation of the mechanical dimensions and the thermal design of the power converter module are explained in addition to the DC-link capacitor design. 

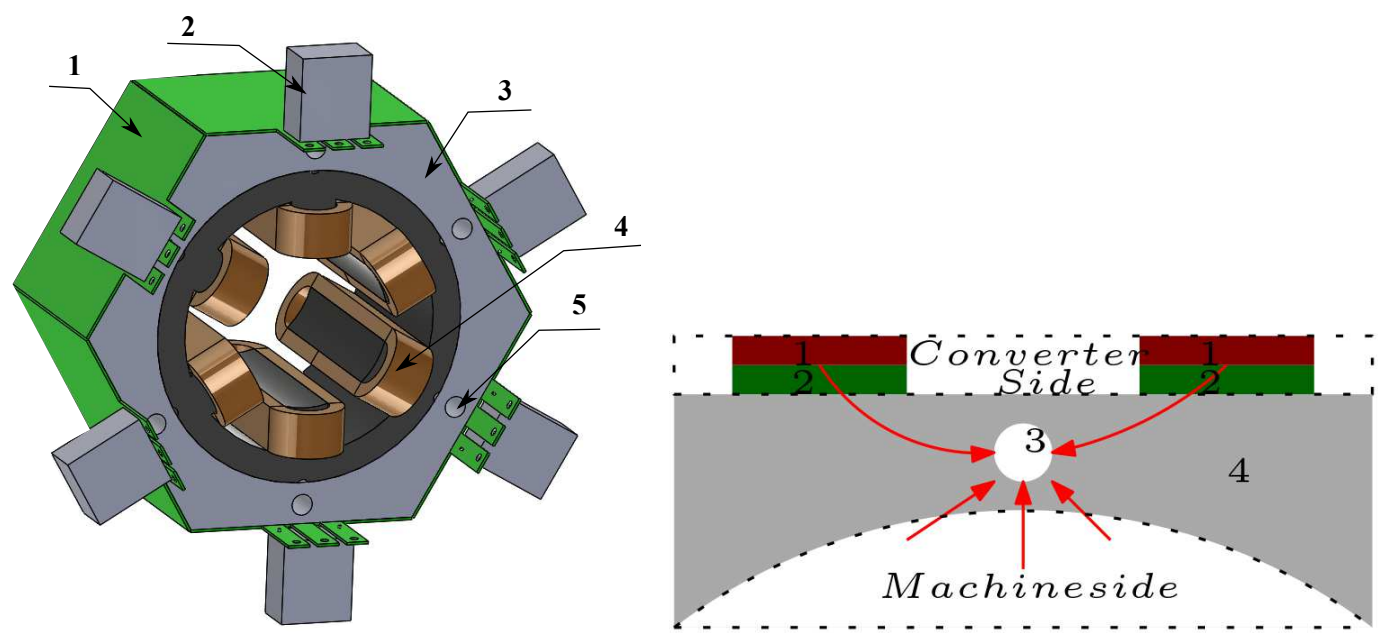

Fig. 1: (left) The proposed IMMD topology for a six teeth concentrated winding machine: (1) Converter PCB, (2) DC link capacitor, (3) Shared cooling structure, (4) One machine tooth, (5) Cooling channel. (Right) The heat flow paths (1) The junction of the transistors, (2) The PCB, (3) The cooling channel, (4) The shared cooling structure.

\section{Mechanical dimensions of the power converter module}

For the design of the power converter module PCB, the converter module dimensions should be calculated first. Since the original axial length of the machine will be maintained, the dimension of the PCB in the axial direction will be the same as the axial length of the machine $\left(L_{y}\right)$. The value of the other dimension $\left(L_{x}\right)$ depends on the radius of the inscribed circle which is the outer housing radius $\left(R_{\text {hout }}\right)$ and the number of stator modules ( $n$ ). From Fig. 2, the value of $L_{x}$ can be calculated from (1).

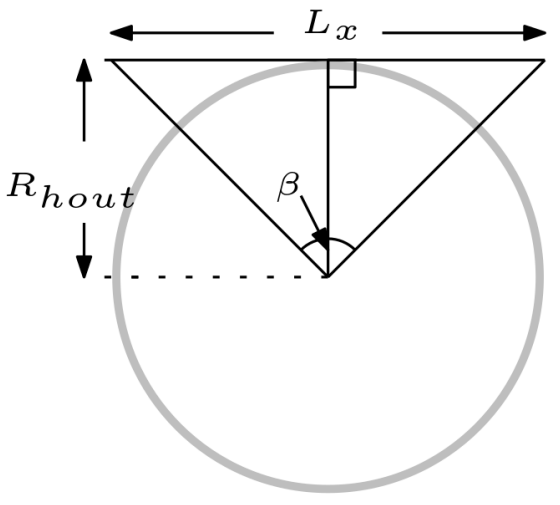

Fig. 2: Calculation of the converter dimension $\left(L_{x}\right)$

$$
\left\{\begin{array}{l}
\beta=\frac{360}{n} \\
L_{x}=2 R_{\text {hout }} \tan \frac{\beta}{2}
\end{array}\right.
$$

A case study with six stator modules machine and $80 \mathrm{~mm}$ axial length will be considered for the converter design. From (1) and the axial length of the machine, the converter module size shouldn't exceed $80 * 87 \mathrm{~mm}^{2}$. For optimal size and efficiency, Gallium nitride $(\mathrm{GaN})$ technology has been selected for the implementation of the converter. The (GS66508B) GaN switch has been selected for the implementation of the half bridge module, the key parameters of the (GS66508B) device are included in Table I. This device has been selected for two reasons, the first one is : its low losses indicated by its small figure of merit $\left(F O M=R_{g} * Q_{g}\right)$ and the zero reverse recovery charge $\left(Q_{r r}\right)$ indicating zero switching losses in the reverse conduction path. The second reason is its small package size $\left(7.1 * 8.5 \mathrm{~mm}^{2}\right)$ 
Table I: GS66508B key specifications

\begin{tabular}{|c|c|}
\hline Property & Value \\
\hline Rated voltage $(\mathrm{V})$ & 650 \\
Rated current $(\mathrm{A})$ & 30 \\
$R_{d s}(\mathrm{~m} \Omega)$ & 50 \\
$\theta_{J C}\left({ }^{\circ} C / W\right)$ & 0.5 \\
$Q_{g}(\mathrm{nC})$ & 5.8 \\
$Q_{r r}(\mathrm{nC})$ & 0 \\
\hline
\end{tabular}

\section{Power converter module thermal design}

From Fig. 1(right), the heat transfer path from the junction of the devices to the coolant includes the PCB layers and the thermal pad electrically insulating the transistors from the shared cooling structure. Minimization of the thermal resistance from the junction to the coolant can be done by distributing a number of thermal vias beneath the thermal pad of the transistor and beyond [10]. In this design, a fourlayer board is chosen for the implementation of the converter. Fig. 3 (left) shows the package layout of the (GS66508B) transistor, pin (2) is the power source pin that receives most of the heat generated in the junction. Fig. 3 (right) depicts the copper area beneath the thermal pad. Zone (1) is the inner zone just beneath the thermal pad of the transistor and zone (2) is added for further reduction of the thermal resistance of the PCB from top layer to the bottom layer.
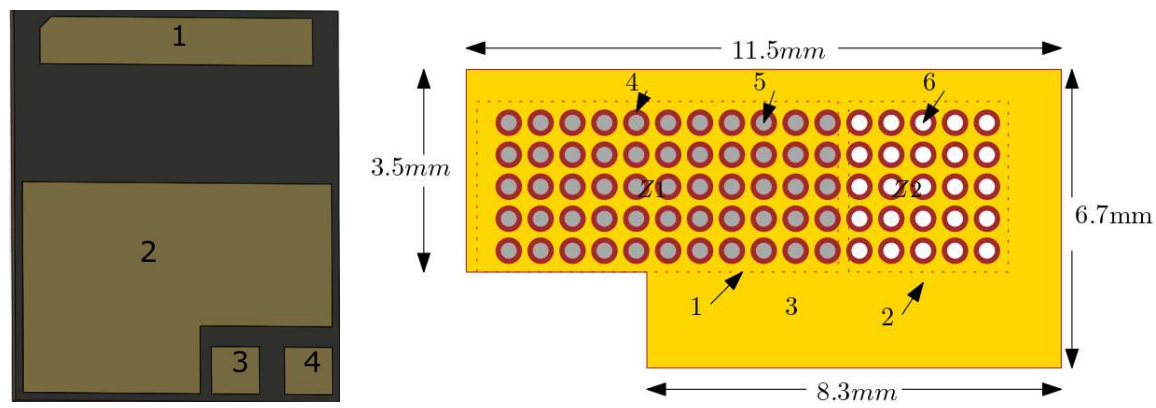

Fig. 3: (left) The (GS66508B) transistor package (1) Drain, (2) Source (thermal pad), (3) Gate, (4) Source sense. (right) Thermal vias pattern: (1) The thermal vias underneath the switch thermal pad (Zone 1), (2) The thermal vias pattern outside the thermal pad (Zone 2), (3) The copper area, (4) The via plating copper, (5) The via filling solder, (6) Air.

For the calculation of the thermal resistance with and without the thermal vias, a thermal model is built. A $1 \mathrm{~W}$ loss is imposed on the thermal pad of zone (1) (see Fig. 3) while the bottom layer temperature is kept at $20^{\circ} \mathrm{C}$. Fig. 4 (left) is the temperature distribution over the PCB without adopting the thermal vias. The maximum thermal resistance from the thermal pad to the bottom layer is $66.99^{\circ} \mathrm{C} / \mathrm{W}$. In Fig. 4 (right), the maximum thermal resistance is $2.18{ }^{\circ} \mathrm{C} / \mathrm{W}$. The thermal via pattern used resulted in $98.7 \%$ reduction in the thermal resistance from the top to the bottom layer.

\section{Design of DC link capacitor}

DC link capacitors are supplying the DC link current pulses resulting from the switching action of the inverter switches [11]. Since, the case study machine has six-stator coils, it can be configured to work as a three-phase or six-phase machine. In case of six-phase machine, the phases can be either connected to have one neutral or it can be divided into two sets of three phase coils (see Fig. 5). For the latter case, interleaving of PWM carriers can be utilized to reduce the DC-link capacitor current stress by proper selection of the interleaving angle $(k)$, see Fig. 6.

Fig. 7 shows the variation of the capacitor rms current with the interleaving angle. The optimal interleaving angle is $90^{\circ}$. 

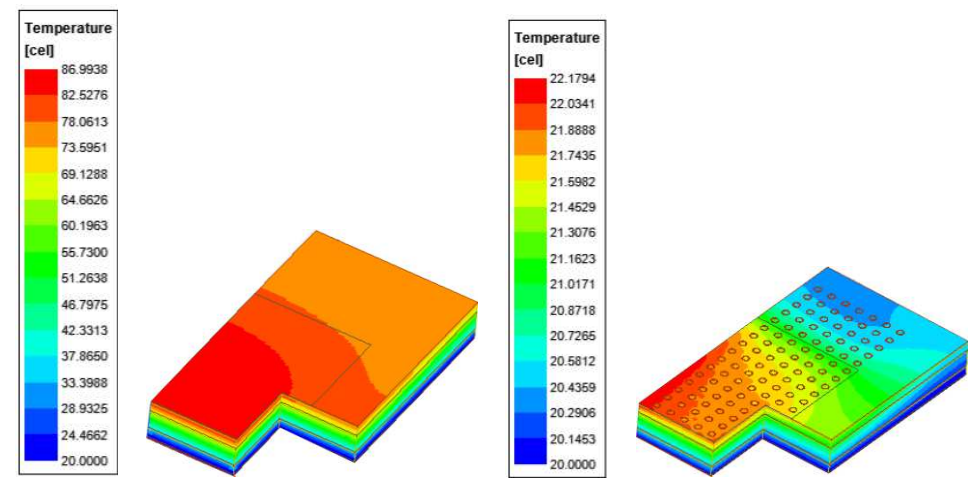

Fig. 4: The temperature distribution under the transistor thermal pad, (left) without thermal vias, (right) with thermal vias.
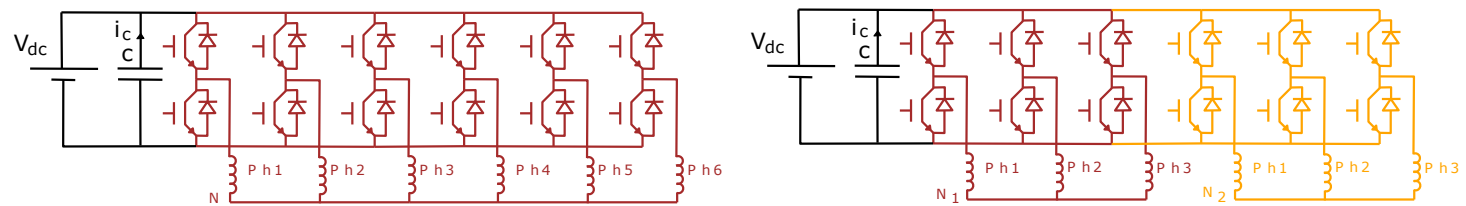

Fig. 5: Configurations of a six phase machine

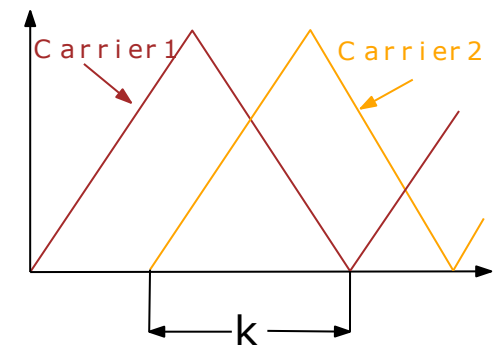

Fig. 6: Interleaved carriers

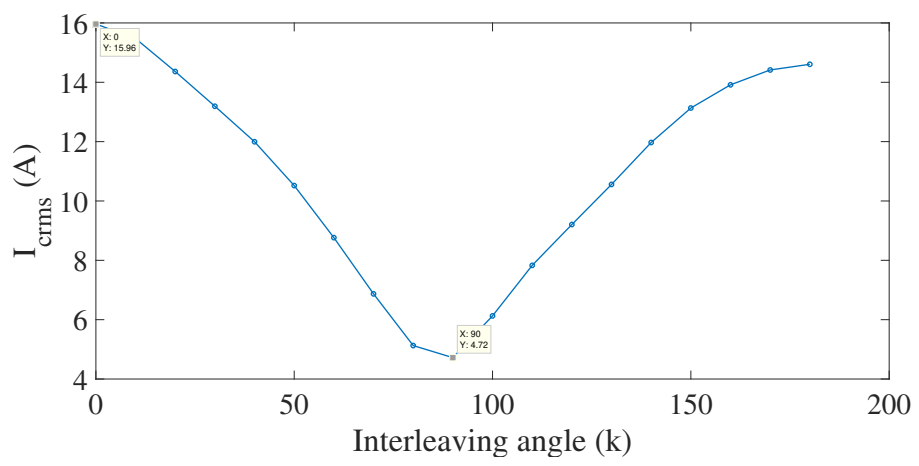

Fig. 7: Capacitor rms current versus the interleaving angle

The DC link capacitance is calculated using (2).

$$
\begin{cases}C & =\frac{\Delta Q}{\Delta V} \\ \Delta Q & =\left.\int i_{c}(t)\right|_{\text {chldisch }} d t\end{cases}
$$

where, $\Delta Q$ is the amount of charge that the capacitor gains or loses every switching cycle, $\Delta V$ is the peak to peak capacitor voltage ripple, $i_{c}(t)$ is the capacitor current during charging or discharging.

The capacitor is sized to have $\Delta V=1 \% V_{d c}$. 
Table II lists the specifications of the capacitor needed for each phase configuration. It can be seen that the six phase configuration with optimal interleaving angle results in the smallest DC link capacitance which can enhance the power density of the whole drive.

Table II: DC link capacitance specifications

\begin{tabular}{|c|c|c|c|}
\hline Configuration & Capacitance $(\mu \mathrm{F})$ & rms ripple current $(\mathrm{A})$ & Rated voltage $(\mathrm{V})$ \\
\hline $3-\phi$ & 10.6 & 8 & 300 \\
$6-\phi, 1$-neutral & 42.5 & 16 & 150 \\
$6-\phi, 2$-neutral & 6 & 4.8 & 150 \\
\hline
\end{tabular}

\section{Thermal design of the circumscribing polygon topology}

The heat transfer rate from both the machine side and the converter side depends on the radius of the cooling channel $\left(R_{\text {cooling }}\right)$ and the flow rate. The value of the cooling radius should be optimized as increasing the cooling radius increases the area through which the heat transfer takes place which enhances the heat transfer rate but at the same time the speed of the coolant at a given flow rate will reduce at the same time. A CFD model has been developed for one module for the optimization of the cooling channel radius. The simulations are done for the channel radii from $2 \mathrm{~mm}$ to $7 \mathrm{~mm}$ considering $5 \mathrm{~W}$ losses in each transistor of the half bridge and 150W losses in one machine tooth. Fig. 8 (left) shows the variation of the convection coefficient of the cooling channel for different channel radii at different flow rates. Fig. 8 (right) depicts the maximum temperature of the transistor thermal pad. From Fig. 8, the optimal channel radius in the chosen range is $2 \mathrm{~mm}$ providing the highest convection coefficient and the lowest transistors temperature.
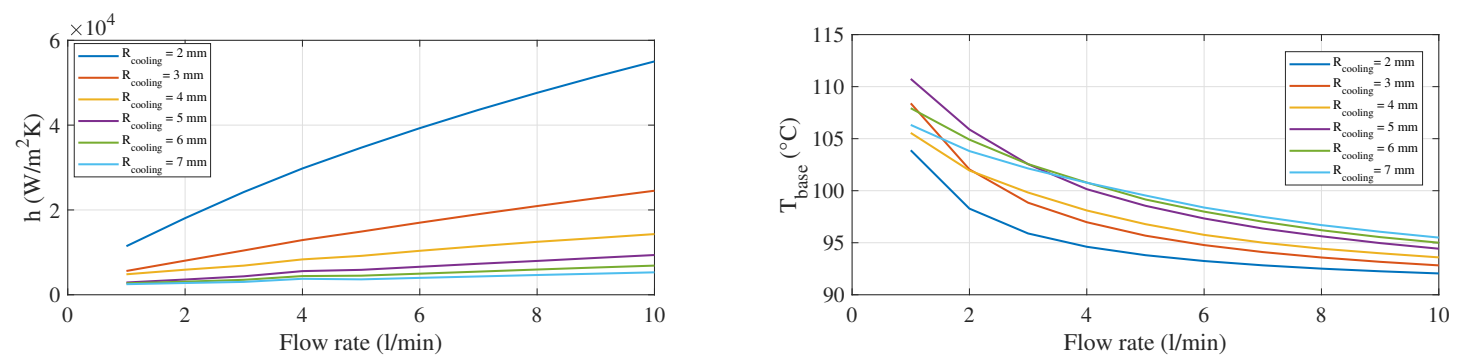

Fig. 8: (left) The convection coefficient versus the flow rate, (right) The transistor thermal-pad temperature versus the flow rate.

Fig. 9 shows the temperature distribution for one integrated tooth at $11 / \mathrm{min}$ flow rate, $87 \mathrm{~W}$ copper losses and $5 \mathrm{~W}$ losses in each transistor. All other surfaces are exposed to natural air convection. From Fig. 9, the peak transistor base plate temperature is $64.3^{\circ} \mathrm{C}$, from the datasheet, the junction to case thermal resistance is $0.5^{\circ} \mathrm{C}$ which makes the junction temperature $66.8^{\circ} \mathrm{C}$. The maximum coil temperature is $88.4^{\circ} \mathrm{C}$.

The thermal properties of the materials of one module are given in Table III. The thermal conductivity of the non-homogeneous parts is given in the three directions $(x, y, z)$ respectively [12]. Here, $C_{p}$ is the specific heat capacity and $\rho$ is the mass density.

\section{Maximum output power per module}

For calculation of maximum output power per module for the proposed integrated topology, the following steps are used:

- From the CFD model, calculate the transistors power losses that result in a junction temperature of $125^{\circ} \mathrm{C}$, a $25^{\circ} \mathrm{C}$ safety margin are left.

- From a developed total transistor power losses (conduction and switching) versus temperature model (see (3) and (4)), at certain operating conditions (fundamental frequency, dc link voltage, 
switching frequency, power factor (PF) ), calculate the peak line current that results in the power losses calculated in (1) at $125^{\circ} \mathrm{C}$ junction temperature.

- Calculate the module power output from $\left(P_{\text {module }}=V * I * P F\right)$, where $V$ is the rms phase voltage, $I$ is the rms phase current. At $1 \mathrm{l} / \mathrm{min}$ flow rate, the transistors power losses that results in $125^{\circ} \mathrm{C}$ junction temperature are $12 \mathrm{~W}$. At the operating conditions in Table IV, the peak line current is calculated to be $18 \mathrm{~A}$, the maximum module output power is $1032.7 \mathrm{~W}$. The total drive power can be calculated by multiplying the module power by the number of modules.

The power losses in the switches can be calculated from (3) and (4) respectively.

$$
\begin{aligned}
&\left\{\begin{aligned}
P_{\text {cons }}= & I_{\text {srms }}^{2} R_{d s}(T) \\
P_{\text {son }}= & V_{d c} f_{o} \sum_{n=1}^{n_{\text {son }}}\left(t_{\text {on }}(n, T) i_{\text {on }}(n)+Q_{r r}(n)\right) \\
P_{\text {soff }}= & V_{d c} f_{o} \sum_{n=1}^{n_{\text {soff }}}\left(t_{\text {off }}(n, T) i_{\text {off }}(n)\right) \\
P_{\text {st }}= & P_{\text {cons }}+P_{\text {son }}+P_{\text {soff }}
\end{aligned}\right. \\
& \begin{cases}P_{\text {cond }}=f_{o} \int_{t}^{t+T_{o}} i_{d}(t) v_{d}(t, T) d t \\
P_{\text {sd }}=0.25 V_{d c} f_{o} \sum_{n=1}^{n_{\text {doff }}} Q_{r r}(n) \\
P_{d t}=P_{\text {cond }}+P_{s d}\end{cases}
\end{aligned}
$$

where, $P_{\text {cons }}, P_{s o n}, P_{s o f f}, P_{s t}$ are the switch conduction, turn on, turn off and total losses respectively, $V_{d c}$ is the DC link voltage, $f o$ is the fundamental frequency of the switch current waveform, $n_{\text {son }}$ and $n_{\text {sof } f}$ are the number of turn-on and turn-off transitions of the switch in one fundamental cycle respectively, $t_{o n}(n, T)$ and $t_{o f f}(n, T)$ are the turn-on and the turn-off time of the switch at the transition number $n$ and temperature $T, i_{o n}(n)$ and $i_{o f f}(n)$ are the switch current at the turn on and off instants respectively, $Q_{r r}(n)$ is the reverse recovery charge of the diode, $T_{o}=\frac{1}{f_{o}}, i_{d}(t)$ and $v_{d}(t, T)$ are the instantaneous current and voltage drop of the diode at temperature $T, P_{c o n d}, P_{s d}, P_{d t}$ are the diode conduction, switching and total losses respectively.

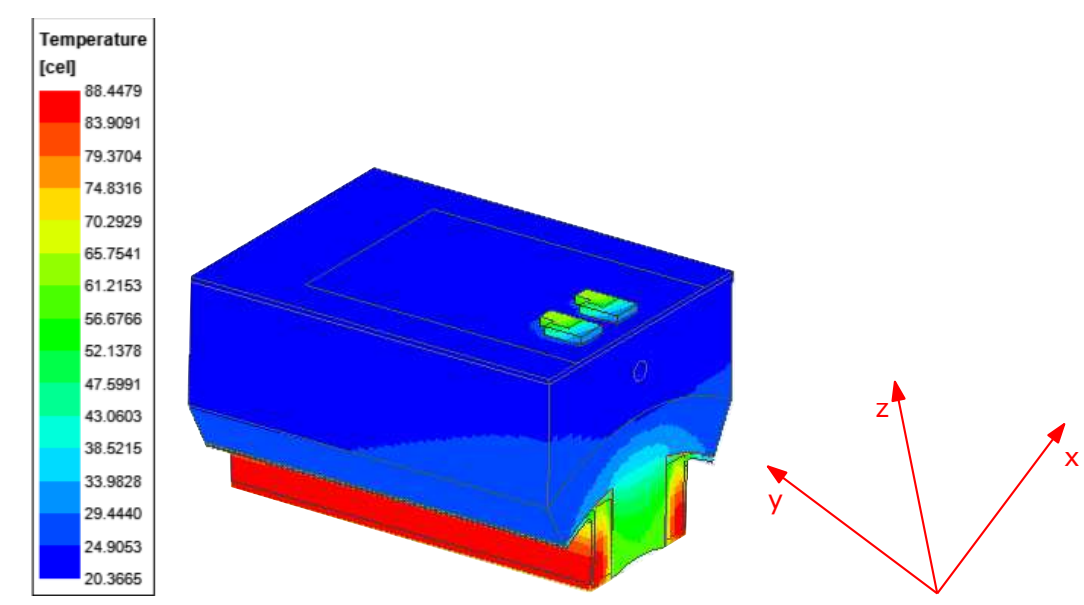

Fig. 9: The temperature distribution for one module at $11 / \mathrm{min}$ flow rate, $5 \mathrm{~W}$ losses in transistors and $87 \mathrm{~W}$ in windings.

Table III: Thermal properties of the materials with the conductivity given in $(x, y, z)$ direction

\begin{tabular}{|c|c|c|c|}
\hline Part & Conductivity $(\mathrm{W} / \mathrm{m} . \mathrm{k})$ & $\mathrm{C}_{p}(\mathrm{~J} / \mathrm{kg} . \mathrm{k})$ & $\rho\left(\mathrm{kg} / \mathrm{m}^{3}\right)$ \\
\hline Winding & $(327.6,2.58,2.58)$ & 393.2 & 7799.3 \\
Core & $(4.9,22.2,22.2)$ & 440 & 7650 \\
PCB & $(5.4,6.4,1.36)$ & 1127.2 & 2523.3 \\
Cooling structure & 237.5 & 951 & 2689 \\
epoxy & 0.21 & 1180 & 440 \\
\hline
\end{tabular}


Table IV: The case study operating conditions

\begin{tabular}{|c|c|}
\hline Variable & Value \\
\hline DC link voltage $(\mathrm{V})$ & 300 \\
Fundamental frequency $(\mathrm{Hz})$ & 333 \\
PF & 0.85 \\
PWM technique & Sinusoidal PWM \\
Switching frequency $(\mathrm{kHz})$ & 50 \\
Modulation index & 0.9 \\
\hline
\end{tabular}
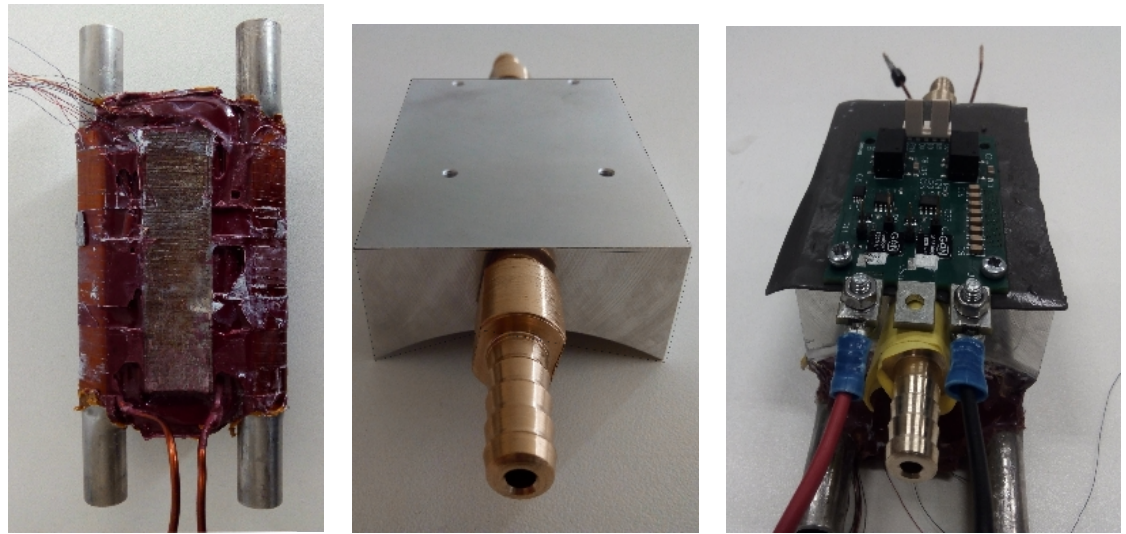

Fig. 10: One integrated tooth setup: (left) One machine tooth, (middle) Shared cooling structure, (right) One assembled integrated tooth

\section{Experimental results}

For validation of the CFD expected transistors temperature based on which the module maximum power was evaluated, a setup consisting of one integrated tooth is built (see Fig. 10).

$5 \mathrm{~W}$ losses are generated in each transistor by connecting them in series with a dc power supply and adjusting the dc voltage until getting a $10 \mathrm{~W}$ total supply output power. $87 \mathrm{~W}$ losses are generated in the tooth coil by the same way. Fig. 11 shows the temperature distribution for the half-bridge converter at $1 \mathrm{l} / \mathrm{min}$. The resulted transistors maximum temperature is $67^{\circ} \mathrm{C}$ indicating good correspondence with the CFD model (See Fig. 9). Note that the low power components around the transistors remain at low temperature which ensures safe operation for the converter.

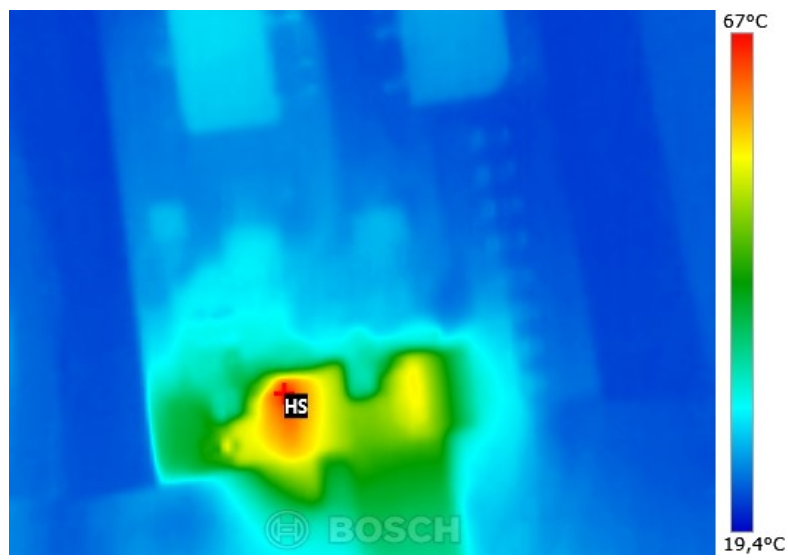

Fig. 11: The measured transistors temperature at $5 \mathrm{~W}$ transistor losses, $87 \mathrm{~W}$ coil losses and $11 / \mathrm{min}$ flow rate. 


\section{Conclusion}

An integrated modular motor drive topology is proposed, designed and analyzed from the mechanical and the thermal point of view. The power converter module is designed and implemented using GaN technology. The designed converter GaN module of size $80 * 87 \mathrm{~mm}^{2}$ is capable of providing up to $1032 \mathrm{~W}$ without violating the thermal or the electrical limits of the components. The DC-link capacitors are designed for every possible winding connections with the smallest DC-link capacitance value and stresses resulting for the six phase windings splitted into two three phase sets at the optimal carrier interleaving angle. A CFD model is built for one integrated module to calculate the maximum power that can be supplied by the proposed topology. A one tooth setup is built to asses the validity of the proposed integrated topology. The CFD model results are in a good agreement with the measurements.

\section{References}

[1] R. Abebe, G. Vakil, G. L. Calzo, T. Cox, S. Lambert, M. Johnson, C. Gerada, and B. Mecrow: Integrated motor drives: State of the art and future trends, IET Electric Power Applications Vol. 10, no. 8, pp. 757771, 2016

[2] Lee, S. Li, D. Han, B. Sarlioglu, T. A. Minav, and M. Pietola: A Review of Integrated Motor Drive andWideBandgap Power Electronics for High-Performance Electro-Hydrostatic Actuators, IEEE Transactions on Transportation Electrification, vol. 4, no. 3, pp. 684693, 2018.

[3] M. Maerz, E. Schimanek, and M. Billmann: Towards an Integrated Drive for Hybrid Traction, pp. $37,2008$.

[4] A. Tenconi, F. Profumo, S. E. Bauer, and M. D. Hennen: Temperatures evaluation in an integrated motor drive for traction applications, IEEE Transactions on Industrial Electronics, vol. 55, no. 10, pp. 36193626, 2008.

[5] B. Ioana, R. Mircea, and S. Lorand: Modular Electrical Machines A Survey, no. 15, pp. 611, 2015.

[6] S. Hazra, S. Madhusoodhanan, S. Bhattacharya, G. K. Moghaddam, and K. Hatua: Design considerations and performance evaluation of $1200 \mathrm{~V}, 100$ a SiC MOSFET based converter for high power density application, 2013 IEEE Energy Conversion Congress and Exposition, ECCE 2013, pp. 42784285, 2013.

[7] M. Trivedi and K. Shenai: Performance evaluation of high-power wide band-gap semiconductor rectifiers, Journal of Applied Physics, vol. 85, no. 9, pp. 68896897, 1999.

[8] K. Shirabe, M. Swamy, J. K. Kang, M. Hisatsune, Y. Wu, D. Kebort, and J. Honea: Advantages of high frequency PWM in AC motor drive applications, 2012 IEEE Energy Conversion Congress and Exposition, ECCE 2012, pp. 29772984, 2012.

[9] M. Maerz, M. Poech, E. Schimanek, and A. Schletz: Mechatronic Integration into the Hybrid PowertrainThe Thermal Challenge, Proc. 1th International Conference on Automotive Power Electronics (APE), no. June, pp. 27, 2006. [Online]. Available: http://www.ecpe.org/download/publications/Paper Maerz APE2006.pdf

[10] Y. Shen, H.Wang, F. Blaabjerg, H. Zhao, and T. Long: Thermal modeling and design optimization of PCB vias and pads, IEEE Transactions on Power Electronics, vol. 35, no. 1, pp. 882900, 2020.

[11] X. Pei, W. Zhou, and Y. Kang: Analysis and Calculation of DC-Link Current and Voltage Ripples for Three-Phase InverterWith Unbalanced Load, IEEE Transactions on Power Electronics, vol. 30, no. 10, pp. 54015412, 2015.

[12] P. Romanazzi, M. Bruna, and D. A. Howey: Thermal homogenization of electrical machine windings applying the multiple-scales method, J. Heat Transfer, vol. 139, no. 1, pp. 18, 2017. 